\title{
CONSTRUÇÃO DE IDENTIDADES PROFISSIONAIS: DA FORMAÇÃO PROFISSIONAL À VIVÊNCIA DA INSERÇÃO NO MERCADO DE TRABALHO
}

\author{
CONSTRUCTION OF PROFESSIONAL IDENTITY: THE EXPERIENCE OF \\ VOCATIONAL TRAINNG IN THE LABOR MARKET INTEGRATION
}

Patricia Whebber Souza de Oliveira*

\section{RESUMO}

Este artigo trata do processo de construção de identidades profissionais no contexto da formação profissional à inserção no mercado de trabalho. Teve como base uma pesquisa qualitativa realizada numa instituição de formação profissional, com a participação de alunos e professores, cujo objetivo foi compreender os processos de socialização e construção de tipos identitários na trajetória de formação profissional à vivência de inserção no mercado de trabalho. Com o enfoque etnográfico e etnometodológico, buscou-se compreender a trajetória escolar e profissional (do início do curso à inserção no mercado de trabalho) através da observação-participante, entrevistas, questionários e análise documental. Como suporte teórico destacou-se as contribuições de Dubar $(1997,1998)$, com seu estudo de configurações identitárias. Os resultados demonstraram que os cursos contribuíram para construção de tipos identitários, principalmente da identidade para 0 trabalho. Esta, por sua vez, quando da vivência de trabalho, foi reconstruída em duas, nova identidade de empresa e nova identidade de oficio. Os tipos identitários encontrados se distinguiram em identidade em formação (trajetória escolar) e identidade em exercício (trajetória profissional).

PALAVRAS-CHAVE: Construção de Identidades - Identidades Profissionais - Formação Profissional

\section{ABSTRACT}

This article deals with the process of professional identity construction in the context of professional education into the labor market. It was based on a qualitative research conducted at an institution of professional education, with the participation of students and teachers, whose objective was to understand the processes of socialization and construction of identity types in the course of the professional education and experience of entering the labor market. With ethnographic and ethnomethodological approach, we sought to understand the educational and professional career (the course starts to move into the labor market) through participant observation, interviews, questionnaires and document analysis. As theoretical support highlighted the contributions of Dubar $(1997,1998)$ with his study of identity configurations. The results showed that the courses have contributed to the construction of identity types, especially the identity for the job. This, in turn, when the experience of work, was rebuilt in two, new corporate identity new occupation identity. The 
identity types found have distinguished themselves in identity in formation (school performance) and identity in exercise (career).

KEYWORDS: Identity Construction - Professional Identity - Professional Education.

\section{INTRODUÇÃO}

Este trabalho trata do processo de construção de identidades profissionais na formação profissional do indivíduo, dos tipos identitários resultantes e de sua continuidade ou ruptura quando da inserção no mercado de trabalho. Teve como base uma pesquisa realizada com alunos e professores de dois cursos, das áreas de turismo e beleza, numa instituição de formação profissional.

A organização do estudo está estruturado em cinco seções: as transformações na sociedade, organização social do trabalho e educação, socialização e construção de identidades profissionais; abordagem metodológica e trabalho de campo; análise e interpretação dos resultados e considerações finais.

\section{AS TRANSFORMAÇÕES NA SOCIEDADE, ORGANIZAÇÃO SOCIAL DO TRABALHO E EDUCAÇÃO}

As transformações ocorridas na Sociedade, caracterizada basicamente pela transição de uma sociedade industrial para pós-industrial, têm exigido uma maior reflexão sobre a organização social do trabalho, as exigências de novas competências e seus reflexos nas relações sociais e na formação identitária do sujeito.

Várias denominações são propostas para esta nova sociedade; como sociedades programadas (MAURICE, 1985); sociedade superindustrial (TOFFLER, 1970); sociedade pós-industrial (BELL apud DE MASI, 2000); sociedade global (IANNI, 1996), sociedade programada (TOURAINE, 1994). Na realidade, as diferentes nomenclaturas são postas em evidência para a compreensão de mudanças profundas que configuram novas características e condições sócio-históricas do desenvolvimento da humanidade.

A emergência do novo modelo de organização social do trabalho foi configurada sob uma relativa dimensão temporal e dentro de condições históricas, sociais e econômicas peculiares. Teve impacto significativo da base técnica e tecnológica do 
próprio desenvolvimento da sociedade como um todo, dentro de uma configuração dialética.

Estas novas formas de organizar o trabalho humano vêm convergindo, apesar de diferentes configurações, para um modelo denominado "modelo de competências" (ZARIFIAN, 1999; PERRENOUD, 1999; FLEURY e FLEURY, 2000). Como ponto de convergência, o modelo de competência teve reflexo da reorganização do modo de produção e de organização do trabalho, que vem exigindo novos perfis do trabalhador, novos arranjos de gestão das organizações e novas formas de pensar a realidade social, do trabalho e da formação profissional.

A educação, neste novo contexto social e do trabalho, assume as responsabilidades e papéis, que vão além da transmissão e construção de conhecimentos teóricos e práticos, perfazendo uma responsabilidade maior na construção e no desenvolvimento de identidades, desde a educação básica a educação superior, além do desenvolvimento de uma consciência crítica e emancipatória do trabalhador.

\section{SOCIALIZAÇÃO E CONSTRUÇÃO DE IDENTIDADES}

Ao longo de sua trajetória biográfica, o individuo passa por numerosos processos de socialização, que refletirá na sua capacidade de interagir com os outros num determinado contexto sócio-cultural.

Ressalta Kruppa (1994) a socialização, que ocorre da interação entre os indivíduos e a sociedade, configura-se como um processo em construção, tendo como agentes, o ser humano e o grupo social; neste processo, o indivíduo se aproxima da conduta do grupo, incorporando certos padrões sociais, e também age sobre o grupo, tendo possibilidade de modificá-lo. A socialização, neste sentido, é um processo permanente, passa a fazer parte do conjunto de experiências do indivíduo.

Postic (1995) considera que a socialização é um processo de aprendizagem de condutas pelo conhecimento que se tem das características das situações, das pessoas, das formas de ação que parecem apropriadas, além do uso nas relações com os outros; essas condutas são fruto da experiência de cada indivíduo.

Para Dubar (1997), o processo de socialização permite compreender a noção de identidade numa perspectiva sociológica restituída numa relação de identidade para si e identidade para o outro. 
Hall (2001, p.7) defende que "as velhas identidades, que por tanto tempo estabilizaram o mundo social, estão em declínio, fazendo surgir novas identidades e fragmentando o indivíduo moderno, até aqui visto como um sujeito unificado" e introduz a noção de crise de identidade como um processo de mudança, deslocando estrutura e processos centrais das sociedades modernas e abalando os quadros de referência de estabilidade do mundo social.

Dubar (1997, p.239) menciona que as identidades estão em movimento e a dinâmica de desestruturação/estruturação pode, às vezes, a forma de "crise de identidade", neste sentido apresenta quatro configurações identitárias baseadas em investigações empíricas francesas, realizadas ao longo dos anos 60 e 80. Para o autor (1997), as formas identitárias resultam da articulação entre a transação objetiva e subjetiva, caracterizam estados de continuidade ou ruptura entre a identidade herdada e visada no âmbito subjetivo, e estados de reconhecimento e não-reconhecimento social no âmbito objetivo, entre a identidade atribuída pelo outro e identidade incorporada para si, conforme demonstrado no quadro 1.

QUADRO 1 - OS QUATRO PROCESSOS IDENTITÁRIOS TÍPICOS

\begin{tabular}{|c|c|l|c|c|}
\hline \multicolumn{2}{|l|}{} & \multicolumn{2}{c|}{ Transação objetiva } \\
\hline $\begin{array}{c}\text { Identidade } \\
\text { para si }\end{array}$ & $\begin{array}{l}\text { Identidade } \\
\text { para outro }\end{array}$ & $\begin{array}{c}\text { Reconhecimento } \\
\text { PROMOÇÃO } \\
\text { (interna) } \\
\text { IDENTIDADE DE } \\
\text { EMPRESA }\end{array}$ & $\begin{array}{c}\text { Não-reconhecimento } \\
\text { BLOQUEAMENTO } \\
\text { (interno) } \\
\text { IDENTIDADE DE } \\
\text { OFÍcIO }\end{array}$ \\
$\begin{array}{c}\text { Transaçã } \\
\text { Subjetiva }\end{array}$ & Ruptura & $\begin{array}{c}\text { CONVERSÃO } \\
\text { (externa) }\end{array}$ & $\begin{array}{c}\text { EXCLUSÃO } \\
\text { (externa) }\end{array}$ \\
\cline { 2 - 5 } & $\begin{array}{c}\text { IDENTIDADE DE } \\
\text { REDE }\end{array}$ & $\begin{array}{c}\text { IDENTIDADE DE } \\
\text { FORA-DO-TRABALHO }\end{array}$ \\
& & &
\end{tabular}

Fonte: Dubar, 1997, p.237.

Os processos identitários típicos anteriormente apresentam as seguintes características: 1) são enraizados na esfera socioprofissional, mas não se reduzem a identidades no trabalho; 2) definem trajetórias diferentes, mas não reduzidas a habitus de 
classe; 3) envolvem categorias oficiais, posições nos espaços escolares e socioprofissionais, mas não se resumem a categorias sociais; 4) são intensamente vividas pelos indivíduos tanto em termos de definição de si com de rotulagens feitas por outros (DUBAR, 1997).

\section{ABORDAGEM METODOLÓGICA E TRABALHO DE CAMPO}

O estudo configura-se sob abordagem etnográfica, caracterizada pela descrição detalhada das percepções, atitudes e comportamentos dos sujeitos, atores sociais, conscientes da realidade cotidiana, com base nas suas vivências interiores, considerando, entretanto a participação do pesquisador, sua compreensão da realidade estudada e o contexto social e educacional onde estão inseridos, expandindo o estudo para um nível macrossocial.

Coulon (1995, p.49) ressalta que o ator social comum é constrangido apreender os níveis macro e micro, simultaneamente na sua vida cotidiana. Assim, propõe a etnografia semiológica, designada posterior etnometodologia (GARFINKEL apud COULON, 1995) que não se limita a simples descrição dos fatos, mas apreensão dos sentidos, que lhes serão atribuídos com base num pressuposto hermenêutico.

Ferreira (2000) sugere que na prática cotidiana, o pesquisador etnográfico deve reconhecer um ciclo próprio deste tipo de pesquisa. Neste sentido, considera duas dimensões concomitantes: o percurso vivenciado pelo pesquisador (prática pessoal) e a epistemologia (teoria do conhecimento).

O estudo procurou estudar os fenômenos dentro do contexto escolar e pedagógico numa dimensão integrada e a partir dos atores envolvidos com a situação real e que deste envolvimento tiram suas próprias percepções e interpretações.

Os procedimentos metodológicos utilizados foram: entrevistas semiestruturadas com 11 alunos durante e após os cursos, e questionários com os 04 professores e 33 alunos, antes, durante e depois da realização dos cursos observaçãoparticipante, caracterizada pela presença do pesquisador no contexto organizacional, escolar e pedagógico, procurando ver o mundo através dos olhos dos sujeitos cuja análise é consolidada através de rubricas ou categorias de análise, descrevendo as principais falas e representações dos sujeitos envolvidos no processo.

Basicamente, estes procedimentos apresentam em comum a participação do 
sujeito e do pesquisador de forma ativa sem a prévia e rígida padronização dos dados a serem coletados.

Os procedimentos metodológicos, em especial o trabalho de campo, seguiram todos os preceitos da abordagem qualitativa, numa dimensão ética e política, respeitando o direito a participação dos sujeitos e reconhecendo sua importância no contexto da pesquisa.

A análise dos dados coletados foi iniciada pela representação do contexto organizacional, para depois, identificar os elementos constitutivos de cada curso, o contexto pedagógico, a proposta e o desenho curricular. Em seguida, o foco da análise se direcionou para os cursos propriamente ditos, com a representação da percepção do aluno e do professor. Ressalta-se que estas representações foram constituídas de forma temporal, no inicio, no final e após a realização dos referidos cursos. Ainda neste enfoque, procuraramse os principais elementos da ação pedagógica que possam justificar as representações anteriormente identificadas.

Além da participação no contexto escolar e pedagógico, foram realizados questionários com todos os alunos ao início e término dos cursos, respectivamente 18 e 10 para o curso da área de Turismo e 15 e 12 para o curso da área de Beleza; com os professores, foram realizados 04 questionários respectivamente. Após o término do curso, mediante a busca de inserção no mercado, foram entrevistados 06 alunos do primeiro curso e 05 de do segundo Além das entrevistas com uma parte dos alunos durante e ao término dos cursos, perfazendo um total de 09 entrevistas para ambos os cursos.

Cabe ressaltar que a coleta e o tratamento dos dados se tornam um processo contínuo paralelo à análise e interpretação dos dados. À medida que o pesquisador interage com os sujeitos, reformula as questões norteadoras iniciais e o processo se autoregula numa dinâmica própria e peculiar. Os dados obtidos foram tratados através da técnica de análise de conteúdo, objetivando contribuir para maior clareza no entendimento das falas dos sujeitos, ora atores sociais, envolvidos no estudo.

\section{ANÁLISE E INTERPRETAÇÃO DOS RESULTADOS CONTEXTO PEDAGÓGICO, SUJEITOS E CONSEQUÊNCIAS}


O curso da área de turismo era estruturado sob a forma de módulos de acordo com a proposta de uma formação profissional baseada na noção de competências.

Apesar de resultados da aprendizagem voltados para o exercício do trabalho, o curso não foi validado pelo mercado, representado pelas empresas do segmento.

No contexto de aprendizagem, foram encontradas limitações em termos de ambiente físico e de condições didático-pedagógicas para a simulação do exercício profissional na sala de aula. Mesmo apresentando características técnicas e intelectuais, o curso não estimulou o desenvolvimento de competências voltadas para inventividade e criatividade, suas atividades dependiam do uso da tecnologia da informática semelhante à realidade encontrada nas empresas, entretanto estas atividades não foram devidamente trabalhadas no decorrer do curso pela falta de software específico, bem como, o domínio de um idioma, outro fator de relevância para inserção no mercado de trabalho.

O curso estava prioritariamente voltado para o domínio de técnicas e procedimentos de trabalho. As competências sócio-organizativas foram trabalhadas transversalmente, sem uma maior dimensão de planejamento pedagógico.

A dinâmica pedagógica otimizava a cooperação através de trabalhos em pequenos grupos e apresentações de trabalho no grande grupo. Os professores, em geral, eram dedicados as suas atividades, tinham uma visão relativamente crítica da realidade do trabalho e das condições para o exercício profissional, mas não deixavam transparecer de forma objetiva para os alunos.

As tarefas eram distribuídas em sala de aula, o professor determinava o ritmo da turma e assumia um papel ativo na concepção da aula, na maioria das vezes, os alunos se tornavam simples espectadores da exposição teórica do professor. O tipo de ensinoaprendizagem foi caracterizado pela dinâmica do grupo, os alunos tinham maior contato com o professor. O ambiente social de sala de aula era descontraído, aberto e acolhedor, entretanto não tão dinâmico em termos de ambiente de formação profissional.

Apesar dos esforços dos professores e da equipe pedagógica, o curso estava configurado para o desenvolvimento de competências técnicas, deixando a desejar na iniciativa para o desenvolvimento de competências sociais, organizativas e políticas.

A maioria dos alunos tinha idade entre 20 e 25 anos, era do sexo feminino e solteiro. O perfil sócio-econômico era relativamente entre médio e alto; em termos comportamentais, os alunos eram alegres, bem apresentados e dinâmicos. Demonstravam 
ter procurado o curso por iniciativa própria, como opção de carreira, para atuar no mercado de trabalho.

Os alunos apresentavam motivações próprias e expectativas em relação ao curso, apresentavam disposição para o processo de aprendizagem, reconhecendo a autoridade e competências do professor; criando com este um vínculo afetivo. Em geral, aceitavam as regras de comportamento social em sala de aula, e nelas se espelhavam para a futura vida profissional. Ainda reconheciam a importância da formação profissional contínua para ter um bom desempenho profissional e conseqüentemente sucesso na área de atuação.

A lógica técnico-burocrática representada pelas empresas não favoreceu a inserção dos alunos no sistema produtivo, e conseqüentemente a consolidação da formação profissional.

Mesmo tendo construído uma identidade profissional, as experiências vivenciadas pelos alunos após o término do curso foram contraditórias em relação às expectativas geradas durante o processo de formação profissional. Tanto que, a maioria dos alunos, optou pela formação profissional em outras áreas, inclusive na opção por um curso superior. Enfim, houve uma ruptura entre o processo educacional e seus resultados com a área de atuação.

O curso da área de Beleza era basicamente dividido em duas partes: a primeira com disciplinas básicas de caráter mais teórico e a segunda, com disciplinas específicas de caráter mais prático. Este estava voltado para o trabalho técnico-manual, foram introduzidos procedimentos e técnicas específicas do trabalho, mas também regras de comportamento social.

Apesar dos professores estimularem a atuação profissional inicial como funcionários de empresas de terceiros, trabalhando ou estagiando num negócio já consolidado, a estrutura e a dinâmica do curso favoreceu a livre iniciativa, a busca de autonomia e do trabalho por conta própria.

Na concepção taylorista, a forma de organizar o trabalho humano tradicional, os trabalhos manuais têm como referência fatores de alienação e fragmentação do trabalho executado, não era o caso deste curso, visto que os alunos desenvolveram todas as atividades do trabalho; o curso era concebido com base na noção de competência, onde a polivalência era estimulada mesmo sob protestos de alguns alunos. 
O ambiente físico e o contexto da aprendizagem, na maior parte do curso, eram semelhantes à estrutura e funcionamento de um ambiente de trabalho, simulando a realidade encontrada no exercício profissional; a disposição dos móveis e equipamentos didático-pedagógicos favorecia a vivência de situações e relações profissionais semelhante às da realidade do trabalho.

Sob esta característica, o diálogo pedagógico tendia a ter maiores situações de ambivalência, pelo jogo social da relação do professor-aluno e de terceiros, os clientes modelos do ambiente-escola; o professor ainda representava o sistema de referência principal, mas a situação pedagógica contribuiu para uma postura mais dinâmica e mais critica do processo educacional.

Os alunos tinham expectativas e motivações iniciais de atuar na área de formação profissional escolhida, principalmente por identificação com 0 trabalho e expectativa de satisfação profissional e financeira.

O perfil sócio-econômico dos alunos era de nível médio e baixo. Em sua maioria, os alunos apresentavam simplicidade e timidez no início do curso, visualizado inclusive na sua apresentação pessoal e comportamentos adotados. Posteriormente começaram a modificar sua aparência, passaram a cuidar da saúde e estética, refletindo a valorização social da profissão pelos alunos semelhante às posições dos professores.

Além de vivenciarem um processo de aprendizagem de conteúdos, técnicas e procedimentos, os alunos começaram a ter uma imagem positiva da área, em especial na contribuição que a atuação profissional eficaz podia trazer para a satisfação das pessoas em geral.

É importante pontuar que os resultados do processo educacional estão compatíveis com a realidade do sistema produtivo desta área, apesar das queixas e reclamações dos alunos, em termos de maior atualização e mais profundidade dos conteúdos e do domínio de técnicas, a lógica do mercado ratificou a base de formação inicial na área e a partir deste a formação profissional adquiriu validade social, ou seja, foi consolidada pela inserção no sistema produtivo.

\section{CONSTRUÇÃO DE IDENTIDADES E TIPOS IDENTITÁRIOS RESULTANTES}

O processo de construção da identidade profissional nos cursos estudados foi 
permeado pela dinâmica de mercado, pela concepção de trabalho e pela posição e status da profissão no contexto social.

Nota-se que a socialização e a construção de identidades, apesar de permear as relações pedagógicas, foram processos postos à margem do processo de ensinoaprendizagem em termos explícitos; permeiam a situação pedagógica, mas de forma inconsciente; não são estimulados, clarificados e muitas vezes, entendidos.

Sob este aspecto, deve-se considerar que a identidade profissional neste estudo, em princípio, pode ser categorizada, pela identidade profissional em formação e identidade profissional no exercício, que adiante serão sub-classificadas em nova identidade de empresa e nova identidade de ofício.

Vale destacar que estes dois tipos de identidade se apresentam como resultantes do processo de formação profissional e do processo de inserção no mercado de trabalho, ou seja, as primeiras experiências profissionais, a possibilidade de consolidação da formação profissional na realidade cotidiana do trabalho e seu contexto.

Neste sentido, o aluno construiu sua identidade sob o olhar do professor e dos demais colegas de curso; inicialmente a sua identidade escolar e posteriormente sua identidade profissional em formação. Estas estão intimamente interligadas, visto que o aluno associa sua identidade profissional, em formação e no exercício da profissão, a sua identidade escolar; sendo esta consolidada pelas expectativas pessoais, do professor e dos demais alunos quanto ao desempenho escolar e pelo próprio resultado do processo de ensino-aprendizagem.

A socialização profissional iniciada na formação profissional estimulou a aquisição de comportamentos profissionais específicos, que deveriam ser postos em prática no exercício profissional; como tem, simultaneamente, caráter permanente e temporário, estes comportamentos modificam-se ao longo das experiências profissionais posteriores, constituindo parte da realidade do mundo de trabalho. A identidade profissional em formação, resultante do processo de formação profissional pode ser ratificada ou modificada ao longo do exercício profissional sob influência e pressão do contexto social e econômico, ou seja, do contexto atual do trabalho.

Também nesta perspectiva, vale destacar que a socialização profissional, como 
base da identificação profissional em formação, não teve elementos constitutivos que a caracterizassem como re-socializações, o processo não se apresentou suficientemente consistente para constituir descontinuidades abruptas na biografia subjetiva do aluno.

O processo de socialização na formação profissional, em ambos os cursos, pode ser classificada como socialização imperfeita, mesmo tendo como resultado uma identidade profissional inicial, implicou no surgimento de diferentes outros significativos no decorrer e posterior a realização dos cursos. Sob este aspecto, apesar das diferentes demandas e das peculiaridades de cada curso, incorreu na aproximação dos alunos com outras realidades, parcialmente observadas, o que configurou uma concepção diferente da identidade profissional em formação.

Nesta perspectiva, no curso da área de Turismo, foi necessário aproximação com outras áreas, através de outros processos educacionais e de novas experiências profissionais para que os alunos desistissem da área de formação inicial, e investissem em novas formações e novas experiências profissionais. No curso da área de Beleza, apesar da permanência e da satisfação com a área, os professores, na ocasião de formações simultâneas e posteriores ao curso, e outros profissionais, passaram a ser mais importante para os alunos, com suas relações e interpretações da realidade profissional;

Em especial, no curso de Turismo ocorreu um desidentificação com o lugar adequado do individuo na sociedade, caracterizado pela impossibilidade de inserção no mercado de trabalho; a estrutura social na qual a profissão está inserida, representada pelas empresas, não permitiu a realização da identidade subjetivamente escolhida, e desenvolvida através do curso de formação profissional, a identidade profissional em formação.

Dessa forma, os alunos não negaram a formação e a identidade construída ao longo do curso, mas objetivamente passaram a investir em outras áreas, o que se pressupõe que ao longo de suas novas experiências estes poderão construir outras identidades profissionais, que passarão a remodelar a identidade profissional, em formação e no exercício profissional, que foi construída no e posterior ao curso, até serem substituídas por novas identidades mais estáveis e consolidadas pela realidade objetiva.

A formação profissional implica em tipos de identidade, que guardam certas semelhanças, são elementos relativamente estáveis da realidade social do trabalho, justamente pela pluralidade de socializações e identificações, permeada pela relação com 
a estrutura da organização do trabalho na sociedade contemporânea, mais complexa e mais instável, pela estrutura da formação profissional e pelas expectativas e imagem subjetiva da realidade do trabalho, da satisfação que se pode obter com e através dele.

As identidades observadas não necessariamente se configuraram em crise de identidade, mas os alunos consideraram a realidade objetiva (inserção no mercado ou a não inserção no mercado) apesar de ter propiciado sentimentos indesejados e frustrantes, classificam suas primeiras experiências profissionais como uma situação natural e temporária.

Mesmo no curso de Beleza, onde os alunos permaneceram na área de formação profissional, as identidades construídas sofreram os impactos das inter-relações e estados mutáveis, entretanto mais harmônicos que no curso de Turismo, ocasionados pela relação com a situação do mercado de trabalho e do mercado de recursos humanos.

Justamente estes estados, mais ou menos harmônicos, são configurados pelas exigências de produção e as antigas lógicas são constantemente reavivadas no dia-a-dia do desempenho profissional.

As identidades construídas, melhor denominadas, os tipos identitários construídos, tornaram-se produtos sociais abertos, não necessariamente fragmentados, nem contraditórios. Basicamente os tipos identitários construídos com base na identidade profissional em formação e a identidade profissional em exercício, seguiram a mesma base contextual do modelo de competências. Estes tipos identitários serão detalhados a posteriori, após a comparação das peculiaridades observadas com os tipos identitários de Dubar (1998).

Sob este aspecto, deve-se considerar que a identidade profissional neste estudo, em princípio, pode ser categorizada, pela identidade profissional em formação e identidade profissional no exercício, que adiante serão sub-classificadas em nova identidade de empresa e nova identidade de ofício.

Diferentemente da concepção da identidade biográfica para si da "identidade de ofício", os alunos consideram que a formação profissional inicial deve ter continuidade, através de formações inovadoras.

Configura-se, então, uma nova identidade de ofício, calcada no "modelo de competências". Nesta, há um sentimento de exclusão antecipatória, caracterizado pela busca incessante de emprego ou de recursos para montar o negócio. 
Seguindo a mesma lógica, na identidade de rede, os alunos são mais individualistas, menos mobilizados para a empresa, desejam a contrapartida da empresa, principalmente em relação às oportunidades.

Na configuração "identidade de rede", os alunos têm a expectativa de "promoção interna", com possibilidade de adaptação dependendo das políticas de recursos humanos da empresa e do próprio mercado. A identidade permanece como identidade em formação, voltada para a adaptação às novas exigências do mercado; em ambos os cursos.

Inicialmente, percebe-se um novo tipo de configuração identitária, calcada no "modelo de competências", uma "nova identidade de oficio" e uma "nova identidade de empresa" cujas características, basicamente, têm aspectos da "identidade de rede" e da "identidade de empresa". Estes tipos identitários apresentam algumas características comuns, que pelas peculiaridades foi denominada identidade para o trabalho.

$\mathrm{Na}$ identidade para o trabalho se encontram as semelhanças entre os dois cursos, neste tipo identitário, a identidade para si é representada pela consideração que os alunos fazem quanto ao investimento e esforço pessoal são a base para o desempenho profissional satisfatório e para o reconhecimento e recompensas profissionais; a identidade para o outro dá sentido a polivalência à medida que os professores associam a sua atuação docente como possibilidade de ter outra profissão, pela experiência acumulada, ressaltando que têm duas áreas de atuação profissional e estão satisfeitos com suas áreas de atuação. $\mathrm{Na}$ identidade relacional, o foco é dado na construção e consciência individual e coletiva, caracterizando o pensamento do grupo em relação ao sucesso, realização e satisfação profissional.

Na nova identidade da empresa em formação, a identidade para o outro está configurada pela importância da participação e do envolvimento dos alunos com o processo de aprendizagem; os professores estimulam a solidariedade e apoio em sala de aula, defendem a perspectiva de que a escolha profissional deve ser reforçada pela busca de qualidade do trabalho e pelo aprimoramento de conhecimentos. A identidade para si está representada pelos alunos pelo alto comprometimento com a aprendizagem, pela participação e envolvimento com o curso e com a sala de aula. Quanto à identidade relacional, os alunos reconhecem que o caminho para atuação no segmento depende da aquisição de uma vaga numa empresa, que depende de suas competências individuais e da conclusão do curso de formação profissional na área para sua realização profissional. 
Na nova identidade de empresa em exercício, a identidade para si está voltada para o reconhecimento da formação profissional; da atuação eficaz dos professores, da importância desta no seu desempenho e resultado escolar; e da percepção positiva em relação ao professores. Quanto à identidade relacional, os alunos tiveram experiências diversificadas na busca de inserção nas empresas. Destaca-se, que como a maioria dos alunos não teve acesso aos estágios e a experiência de uma relação empregatícia, esta identidade é mantida pela experiência da aprendizagem, compensada pela valorização da área, do curso e dos professores, minimizando a frustração pela ausência de inserção no mercado. A identidade para o outro não foi identificada por não terem sido inseridos outros atores sociais, tais como representantes das empresas e colegas de atuação profissional.

$\mathrm{Na}$ nova identidade de ofício em formação, a identidade para o outro é constituída pela alta valorização social da área; pelo estimulo à participação e envolvimento com os serviços a serem prestados aos clientes. Na identidade para si, neste tipo identitário, os alunos reconhecem o valor social de sua futura atividade profissional. $\mathrm{Na}$ identidade relacional, os alunos valorizam as competências dos professores, entretanto, consideram a precariedade do curso, a limitada praticidade e relativa segurança para o exercício profissional.

Na nova identidade de ofício em exercício, a identidade para si é constituída, basicamente, pelo espírito empreendedor, pelos caminhos percorridos diversificados, pela adequação a sua realidade social e financeira ao montar o próprio negócio e pelos sentimentos de complementação de seus conhecimentos._Em termos da identidade relacional, os alunos reconhecem que o dia-a-dia da profissão é dinâmico, crítico e de alta responsabilidade; continuam tendo uma percepção positiva, em especial afetiva, dos professores. Não foi analisada a identidade para o outro, considerando que para tal era necessária a participação de outros atores sociais, conforme detalhado no quadro 2.

$\begin{aligned} & \text { QUADRO } 2 \\ & \text { CARACTERÍSTICAS }\end{aligned}$ TIPOS IDENTITÁRIOS
E PECULIARIDADES




\begin{tabular}{|c|c|}
\hline $\begin{array}{l}\text { Busca pelo espaço de traba } \\
\text { Sucesso, realização e } \\
\text { competências individuais } \\
\text { Investimento contínuo em cc } \\
\text { Sentimentos de falta de com }\end{array}$ & $\begin{array}{l}\text { satisfação profissional associados } \\
\text { hecimento }\end{array}$ \\
\hline $\begin{array}{l}\text { NOVA IDENTIDADE DE } \\
\text { EMPRESA (ÁREA DE } \\
\text { TURISMO) }\end{array}$ & $\begin{array}{l}\text { NOVA IDENTIDADE DE OFÍCIO (ÁREA DE } \\
\text { BELEZA) }\end{array}$ \\
\hline 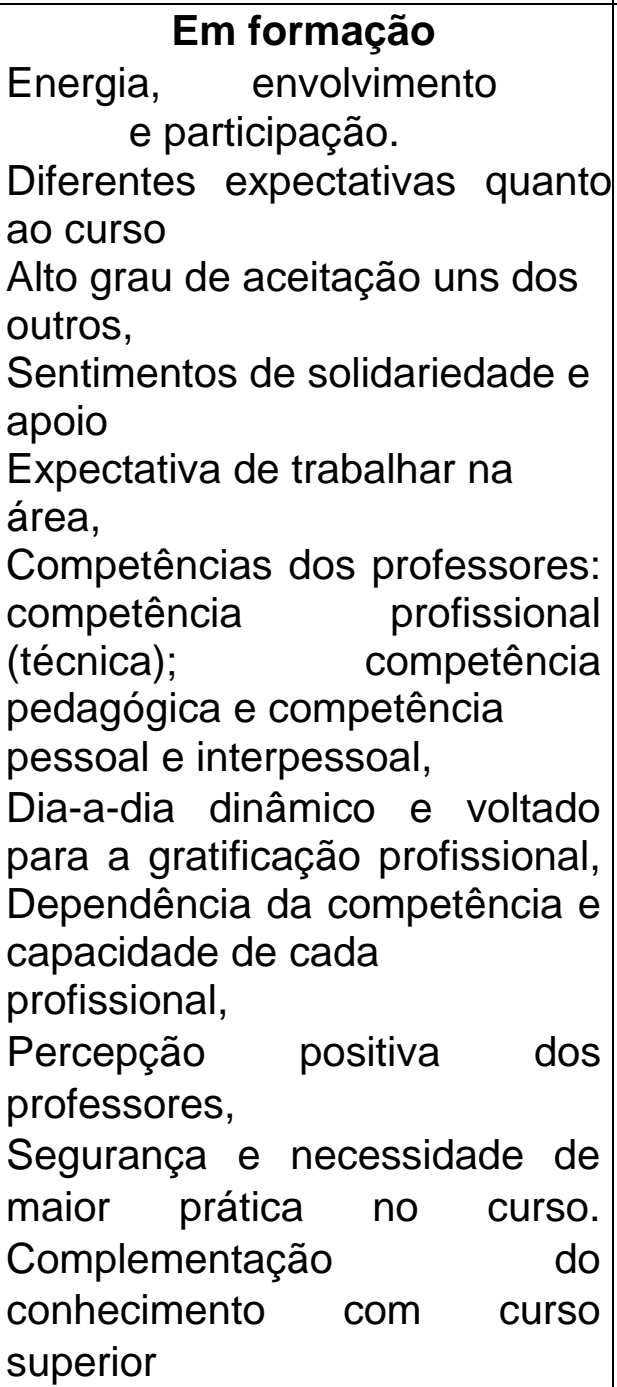 & $\begin{array}{l}\text { Em formação } \\
\text { Envolvimento, espírito crítico e participação. } \\
\text { Expectativas do próprio negócio } \\
\text { Relativa aceitação uns dos outros, } \\
\text { Percepção do curso com alicerce profissional } \\
\text { e carreira } \\
\text { Busca da livre iniciativa e trabalho autônomo, } \\
\text { Competências dos professores: competência } \\
\text { profissional (técnica); competência } \\
\text { pedagógica e competência pessoal e } \\
\text { interpessoal, } \\
\text { Dia-a-dia dinâmico, difícil e importante, } \\
\text { Precariedade do curso, limitada praticidade e } \\
\text { limitada segurança para desempenho } \\
\text { profissional, } \\
\text { Percepção positiva dos professores, } \\
\text { Aquisição de competências como } \\
\text { estabilidade no trabalho, } \\
\text { Complementação do conhecimento com } \\
\text { cursos semelhantes }\end{array}$ \\
\hline
\end{tabular}




\begin{tabular}{|l|l|}
\hline \multicolumn{1}{|c|}{ Em exercício } & \multicolumn{1}{c|}{ Em exercício } \\
Experiência profissional \\
diversificada e negativa Ruptura \\
entre formação & Experiência profissional diversificada \\
profissional e inserção no & Continuidade da formação profissional e \\
mercado & inserção no mercado \\
Percepção positiva dos professores em termos & afetivos \\
Condiçães de trabalho & Sentimentos de complementação \\
incompatíveis com as & expectativas Percepção positiva \\
do professores em termos & Permanência na área de formação \\
técnicos e afetivos Sentimentos & profissional \\
de complementação & Busca de aperfeiçoamento e investimento na \\
Mudança na área de atuação & área de atuação \\
Busca de formação profissional & \\
em outras áreas & \\
\hline
\end{tabular}

Fonte: Primaria, 2007.

Cabe ressaltar que as escolhas profissionais dos alunos se limitaram aos apelos da realidade imposta pela sociedade e aos da própria instituição de formação profissional, sendo reforçada ao longo do curso pelos professores pela identificação com a área e pela própria defesa de sua condição sócio-profissional.

Destaca-se, assim, que a qualidade da formação profissional em termos de consistência e coerência com a realidade social e econômica implica em diferentes resultados da ação pedagógica em termos de construção de identidades profissionais que possam realmente ser consolidadas no posterior exercício profissional.

Nota-se que apesar dos esforços da Instituição para a adequação dos cursos às exigências do mercado e do contexto sócio-econômico atual, há paradoxos e contradições entre os processos e as condições pedagógicas identificadas e os resultados alcançados quando da inserção dos alunos na vida produtiva.

\section{CONSIDERAÇÕES FINAIS}

Os limites da formação profissional vão além do desenvolvimento de competências técnico-operacionais, uma vez que englobam outros aspectos da vida social e da vida organizativa; interferindo na construção de identidades profissionais que precisam ser ratificadas quando da inserção do aluno no mercado de trabalho.

Quanto mais sólida a qualidade da formação profissional, maior a probabilidade 
de construção de identidades profissionais mais realistas e maior a contribuição do referido processo para a inserção no sistema produtivo, para a (re) adaptação ao exercício profissional, de forma consciente, crítica e satisfatória.

Na busca de maior compreensão dos impactos da ação pedagógica na trajetória pessoal do aluno sob influência da ação pedagógica, optou-se pela abordagem metodológica que permitisse a participação dos atores sociais envolvidos no processo da formação profissional e da inserção no sistema produtivo.

Notou-se que, em geral, ambos os cursos consolidaram a construção de uma identidade profissional (denominada no estudo de identidade profissional em formação) ao término do curso. Desta forma, o aluno constrói sua identidade sob o olhar do professor e dos demais colegas de curso; primeiro sua identidade escolar e depois a sua identidade profissional em formação.

Em nenhum momento, os alunos negaram a identidade profissional construída ao longo dos cursos, com base nas experiências posteriores; modificaram em termos de complementação ou de ruptura às suas escolhas e investimentos profissionais, com base nas contrapartidas que oportunamente tinham ou não no mercado.

Na dimensão pedagógica, destaca-se essencialmente a atuação do professor, como mediador da relação ensino-aprendizagem e como "outro significativo", na transmissão de conhecimentos, valores e atitudes profissionais, que refletirá como fator decisivo no processo de formação identitária do indivíduo.

Ressalta-se que a formação profissional é um processo mais complexo do que aparentemente demonstra. Educar para o trabalho não se limita a instruir, envolve elementos intrínsecos, muitas vezes "ocultos" que vão além da dimensão objetiva. E que, quanto mais sólida e responsável a missão de educar, quanto mais consistente a formação profissional, maiores são as possibilidades de construir identidades profissionais realistas e maior a contribuição para um exercício profissional responsável, consciente e satisfatório, tanto em termos individuais como em termos sociais.

\section{REFERÊNCIAS BIBLIOGRÁFICAS}

COULON, Alain. Etnometodologia e educação. Tradução Guilherme João de Freitas Teixeira. Petrópolis, RJ: Vozes, 1995. 
DE MASI, Domenico (Org.). A sociedade pós-industrial. 3 ed. Tradução Anna Maria Capovilla, Luiz Sergio do N. Henriques, Marco Aurélio Nogueira, Maria Cristina G. Cupertino, Renato Ambrósio. São Paulo: Editora Senac, 2000.

DUBAR, Claude. A socialização: construção das identidades sociais e profissionais. Tradução. Anette Pierrette R. Botelho e Estela Pinto R. Lamas. Portugal: Porto editora, 1997.

DUBAR, Claude. Socialização e construção de identidades. Tradução-livre Adir Luiz Ferreira. L'identité, l'individu, le groupe, la société. Jean-Claude Ruano-Borbalan. Auxerre: Ed. Sciences Humaines, 1998.

FERREIRA, Adir Luiz (Org.). O educador e o pesquisador: a escola é uma tribo? In: $O$ cotidiano escolar e as práticas docentes. Natal, RN: EDUFRN, 2000.

FLEURY, Afonso; FLEURY, Maria Teresa Leme. Estratégias empresariais e formação de competências: um quebra-cabeça caleidoscópico das indústrias brasileiras. São Paulo: Atlas, 2000.

HALL, Stuart. A identidade cultural na pós-modernidade. 6 ed. Tradução Tomaz Tadeu da Silva, Guarcira Lopes Louro. Rio de Janeiro: DP\&A, 2001.

IANNI, Octavio. A sociedade global. 4 ed. Rio de Janeiro: Civilização Brasileira, 1996.

KRUPPA, Sonia M. Portella. Sociologia da educação. São Paulo: Cortez, 1994.

MAURICE,Marc. O determinismo tecnológico na sociologia do trabalho (1955-1956): uma alteração de paradigma?. In: Sociologia do trabalho: organização do trabalho industrial. Antologia. Tradução Maria Alexandra F. Costa e Sousa e Teresa Saraiva. Lisboa, Portugal: A regra do jogo edições, 1985. 
PERRENOUD, Phillipe. Construir as competências desde a escola. Tradução Bruno Charles Magni.Porto Alegre: artes médicas, 1999.

POSTIC, Marcel. Para uma estratégia pedagógica do sucesso escolar. Tradução Maria Isabel Lopes. Portugal: Porto, LDA, 1995.

TOFFLER, Aldin. O choque do futuro. 3 ed. Tradução Eduardo Francisco Alves. Rio de Janeiro: Record, 1970.

TOURAINE, Alain. Crítica da modernidade. Tradução Elia Ferreria Edel. Petropólis, RJ: Vozes, 1994.

ZARIFIAN, Phillipe. El modelo de competência y los sistemas productivos. Montevideo: Cinterfor, 1999.

ENVIADO EM: 12.09. 2011

APROVADO EM: 26.11. 2011

* Graduada em Psicologia pela UFRN (1988) e em Administração pela UnP (2010), Mestra em Administração pela UFRN (1997) e Doutora em Educação pela UFRN (2003). Professora do Mestrado Profissional em Administração - Universidade Potiguar - UnP. 